\section{A global call to arms}

\section{A seminal report on climate change deserves the world's attention.}

t is fitting that Nicholas Stern, a British civil servant and former chief economist at the World Bank, should have presented his report on the economics of climate change at the Royal Society in London. For it was in a speech to the Royal Society 18 years ago, that Margaret Thatcher, then Britain's prime minister, became the first world leader to call for serious attention to be paid to the possibility of global warming.

That famous speech, although addressing science, was at heart political; so, in many ways, is Stern's review. It articulates a consensus on the need for action that Britain, thanks in part to Thatcher's remarks, has had longer to develop than many other nations. Its political nature should not, however, be seen as a flaw. Climate change is a matter of political choices, and the discussions that surround it must be political. Stern's review is an important contribution to that discussion (see pages 6-7).

Stern's review, which was commissioned by Gordon Brown, currently Britain's chancellor of the exchequer and in all likelihood its next prime minister, is almost as striking in its assumptions as in its conclusions. It insists, contrary to some utopian activists, that adverse consequences of climate change are unavoidable. In its choice of targets and assumptions, it tacitly supports the idea that the most feasible goal is one of stabilizing the level of greenhouse gas at roughly

twice the pre-industrial carbon dioxide level. Following through on the logic of this, Stern's review has almost as much to say about the economics of adapting to climate change as about the economics of mitigating it.

On mitigation, Stern concludes that the investment needed to control climate change is small compared with the costs of allowing it to continue unabated. The estimates of those costs are stated with more confidence than they would be in the scientific literature, and the review should not be taken as the last word on this. But the robust message is that the costs of mitigation, although vast, are manageable if efficient policies to put a price on carbon emissions are spread around the globe. The European emissions trading scheme might provide a nucleus for such pricing, although there are other possibilities.

The review also stresses the value of subsidies to help clean technologies establish themselves in the marketplace, and the importance of doubling research spending on energy issues. On

"The investment needed to control climate change is small compared with the costs of allowing it to continue unabated." both matters, its content should be noted by the people of California, who next week vote on Proposition 87, an initiative to establish a fund of $\$ 4$ billion ( $£ 2.1$ billion) to spend on such support and research. A pre-allocated fund is not the ideal way to approach these issues, but it is the one on offer. Establishing it should help the development of clean technologies in California, and allow the state's citizens to declare their desire to move away from fossil-fuel dependency. It would therefore be a good proposition to pass.

\title{
Enough biodefence
}

\section{Who wants a bioweapons lab next door?}

Finatis ive years ago, in the aftermath of the attack on the World Trade Center, anthrax was found in the mail in several locations in the United States. The discovery heightened fears that the country was vulnerable to bioterrorist attack. Subsequently, the federal government has, according to the Center for Arms Control and Non-Proliferation in Washington DC, spent a staggering \$36 billion on biosafety-related activities.

Criticism of this approach was muted back in 2001, but five years on it is surging in the communities designated to host biosafety labs. Despite protests, however, the government is accelerating its investment in the biodefence complex that is now taking shape.

Last May, residents of Boston's Roxbury district sued the Boston University Medical Center and the National Institutes of Health (NIH) to try and block the construction of a \$178-million biodefence laboratory there. The lab, which will be equipped to perform experiments at biosafety level 4 - the highest classification of confinement is already under construction. Last month, a district-court judge declined to halt the building work, but reserved the right to stop the project later on, subject to the results of an environmental review that the NIH has already agreed to perform.
The court's ruling suggests that the NIH and Boston University failed to adequately assess the environmental consequences of building such a lab in the middle of a large conurbation. A similar omission appears to have been made by the Department of Energy, which wants to construct a biosafety level $3 \mathrm{lab}$ at the Lawrence Livermore National Laboratory in California - a site virtually surrounded by suburban sprawl. An appeal court there ruled last month that the energy department has yet to conduct a sufficiently thorough assessment of the laboratory's risks, particularly regarding the risk of a terrorist attack on the site itself.

These cases follow protests against a new biosafety level 4 lab being built by the Department of Homeland Security (DHS) at Fort Detrick, Maryland, as part of a \$105million National Biodefense Analysis and Countermeasures Center. And they offer a taste of what's to come with another DHS project, a planned \$450-million National Bio and AgroDefense Facility, as yet unlocated.
"The proliferation of such labs begs the broader question of how much biodefence is too much."
These objections have concentrated on local questions, but the proliferation of such labs begs the broader question of how much biodefence is too much. In the febrile climate of 2001, the Bush administration wasn't pressed sufficiently to explain why such proliferation of knowledge is in the national interest. Five years on, the time has come for it to do so. 